\title{
The Role of Optimism in experience of Student Stress and Suicidal Ideation
}

\author{
${ }^{1}$ Dr. Hameeda Shaheen and ${ }^{2}$ Dr. Musaddiq Jahan \\ ${ }^{I}$ Post Doctoral Fellow (PDF; ICSSR), Department of Psychology, Aligarh Muslim University, Aligarh, Uttar \\ Pradesh, India. \\ ${ }^{2}$ Associate Professor, Department of Psychology, Women's College, Aligarh Muslim University, Aligarh, Uttar \\ Pradesh, India.
}

\begin{abstract}
Suicidal behavior and ideation among adolescents is prevalent problems in almost every country that warrant considerable attention. While a variety of factors have been linked to suicidal ideation, only few studies have examined role of stress and optimism among adolescents population. This study aimed to determine the relationships between stress and optimism and suicidal ideation among adolescent students. Participants for this study were 200 adolescent students from Aligarh Muslim University, Aligarh, India. Appropriate questionnaires were used for measuring optimism, stress, and suicidal ideation among students. Apart from descriptive statistics for analyzing data, a four-step hierarchical linear regression analysis was used in order to examine main and moderator effects predicting suicidal ideation. Significant moderating effects were also probed and plotted through simple slopes at plus-and-minus one standard deviation of the stress on the association between stress and suicidal ideation within each level of moderator variable i.e. high and low levels. The results of the Pearson's correlation analysis showed that there was significant positive relationship between stress and suicidal ideation. A significant negative correlation between optimism and suicidal ideation was also found. In addition, boys were more pessimistic and had more suicidal ideation compared to girls. Hierarchical regression analyses showed that stress and optimism predicted suicidal ideation for total sample and for both boys and girls. Moreover, the Stress X Optimism interaction was found to further augment the prediction of suicidal ideation, even after controlling for demographic variables and the main effects of optimism and stress. Consistent with the proposed interaction model, a plot of the significant interactions indicated that the link between stress and suicidal ideation was significantly more exacerbated for pessimistic as compared to optimistic adolescents. Findings from this study would help the health-care professionals, counsellors, teachers, and parents in understanding how high stress which is peculiar to the stage of adolescence particularly students may have serious consequences in the form of suicidal ideas and that optimistic thinking may be helpful in coping with the stresses of this stage so as to avoid its harmful effects.
\end{abstract}

Keywords: Adolescents; Stress; Suicidal Ideation; Optimism.

\section{Introduction}

Suicidal ideation and suicidal behaviour among students in the age of adolescence is a worldwide problem that warrants considerable attention. Life for many adolescents is not easy and adolescence is considered by many as period of storm and stress. Developmental and neurobiological substrates are combined with the conflicting demands from parents, teachers, and friends. High level of parental expectations, academic demands, adjustment to new situations, school and college environment, peer pressure, break-up with boy / girl are some of the most common events in the life of a student which for some, may lead to serious consequences resulting in suicidal behaviour.

In present era psychologists are more concerned about adolescents' problems because in the current age of modernization, adolescent population is facing a large number of problems due to high level of parental expectation, parental pressure, and academic demand, adjustment of new situations, school and college environment, and peer pressure, physical and mental changes and growth etc. According to Kumar and Singh (2006), student life faces several ups and downs. For the students which create stressful life for them are peer pressure, demands of the teachers and parents for the good grades, and the competitive environment in the school. This stressful life leads to depression, anxiety and in several cases causes suicide and suicidal attempts among students.

\section{Suicidal Ideation}

Suicidal behavior is an important public health problem worldwide and official statistics in United States suggest that suicide is the third leading cause of death in the 15 to 19 age group (Reynolds, 1988). In Asian societies like Hong Kong, Taiwan, and Singapore, the prevalence begins to increase for youth between 10 
to 14 years of age, and in the 15 to 24 age group, there is a dramatic increase in absolute numbers (Chia, 1999; Ung, 2003). According to the National Crime Records Bureau in 2013, 'around $34.4 \%$ suicide victims were youths in the age group of 15-29 years.

Researchers have sought to understand, predict, and prevent suicide by examining the potential contributions of psychological factors to suicidal thoughts and behaviors. Much of this research has focused upon risk factors and psychopathological predictors of suicidal thoughts and behavior with far less attention paid to protective factors, mirroring a general trend in the mental health literature of focusing on pathology rather than on strength and resiliency (e.g., Seligman \& Csikszentmihalyi, 2000). Thus, it seems particularly important to research risk factors for suicidal behavior, as well as factors that may protect against suicidal behavior, with the ultimate goal of preventing needless injuries and deaths. The present study was conducted to explore the role of stress and optimism in relation to suicidal ideation among adolescents.

According to O'Carroll et al. (1996), suicidal ideation is defined as self reported wishes, thoughts, or desire to take one's own life. Suicide is the completed process of a continuum that begins with suicidal ideation, followed by an attempt of suicide, and finally completed suicide (Cole, Protinsky, \& Cross, 1992). Suicidal ideation is a preoccupation with instructive thoughts of ending one's own life (Cole et al., 1992; Harter, Marold, \& Whitesell, 1992).

\section{Stress}

Stress is an important factor which plays an important role in the development of suicidal behaviour. Baum (1990) described stress as "a negative emotional experience accompanied by predictable biochemical, physiological, and behavioral changes that are directed toward adaptation either by manipulating the situation to alter the stressor or by accommodating its effects". The theoretical orientations for explaining stress have been categorized into three types: response based, stimulus based, and transactional based. Selye (1956) defined stress as the "nonspecific response of the body to noxious stimuli". Stimulus-based definitions of stress refer to stress as an independent variable that elicits some response from the person. The rationale of this approach is that some external forces impinge on the organism in a disruptive way (Masuda \& Holmes, 1967; Holmes \& Rahe, 1967). According to Lazarus and Folkman (1984), stress is defined by the person's perception of the environmental event, this perception involves the appraisal of potential harm, threats, and challenges posed by the event, as well as the individual's perceived ability to deal (or cope) with the harms, threats and challenges. Similarly Sarafino (1994) defined stress as the condition that results when person/environment transaction leads the individual to perceive a discrepancy - whether real or not - between the demands of a situation and the resources of the person's biological, psychological or social system."

\section{Optimism}

Optimism is a very important protective factor which plays positive role in development of good mental health and wellbeing. On the basis of large number of research conducted on optimism, psychologists suggested that optimism exert a direct protective effect against suicidal ideation (Hirsch, Conner, \& Duberstein, 2007; Hirsch et al., 2007a; Roberts, Roberts, \& Chen, 1998). Optimism also function as a protective factor in the presence of adversity and decrease suicidal ideation (Blankstein, Lumley, \& Crawford, 2007; Hirsch, Wolford, LaLonde, Brunk, \& Morris, 2007; Hirsch \& Conner, 2006; Hirsch et al., 2007b), suggesting that risk factors are more likely to relate to poor outcomes among those with an impoverished optimism.

Dispositional optimism is defined as individuals' stable, generalized expectations that they will experience good things in life. Scheier and Carver (1992) defined optimism as dispositional characteristics or a personality trait comprised of a positive mood or attitude about the future and a tendency to anticipate a favourable outcome to life. They believe that optimism is a dispositional characteristic or life orientation to life events and some people are by nature optimistic while others are pessimistic. Optimism enables individuals to restore their efforts to reach goal when faced with obstacles (Scheier, Weintraub, \& Carver, 1986).

Cato (2012), among 30 African American college students (ages 18-28 years), found a significant negative relationship between optimism and suicide. Similarly in a recent study, Sánchez-Teruel, García-León, \& Muela-Martínez (2013) showed that students more likely to have suicidal ideation are less optimistic, have poorer social skills and less social support.

\section{Aims and Hypotheses}

To date there is little research with adolescents on how optimistic views about future and suicidal ideation are related. Therefore, this study sought to explore how low optimism and stress are associated with suicidal ideation. An additional purpose was to explore whether optimism may act as a moderating or buffering factor in the relationship between stress and suicidal ideation. In order to achieve the above aims the following hypotheses were formulated:

1. There will be positive predictive relationship between stress and suicidal ideation. 
2. Optimism will have negative predictive relationship with suicidal ideation.

3. The relationship between stress and suicidal ideation will be stronger for adolescents with low optimism than for those with high optimism suggesting that optimism will moderate the relationship between adolescent stress and suicidal ideation.

4. Predictors of suicidal ideation for boys and girls will be different.

\section{Participants}

\section{Method}

The sample of the present study consisted of 200 adolescent students (100 males and 100 females) randomly selected from Aligarh Muslim University (AMU), Aligarh. This was a convenience sample and the participants were from Grade IX through XII students. The age of the subjects ranged from 13 to 21 years with a mean age of 15.9 years. A summary of the demographic characteristics of the sample is provided in Table 1.

Table 1: Demographics Characteristics of the sample $(\mathrm{N}=200)$

\begin{tabular}{|c|c|c|c|c|}
\hline & Frequency & $\begin{array}{l}\text { Percentage } \\
\text { of total sample }\end{array}$ & Mean & SD \\
\hline \multicolumn{5}{|l|}{ Gender } \\
\hline Males & 100 & $50 \%$ & & \\
\hline Females & 100 & $50 \%$ & & \\
\hline \multicolumn{5}{|l|}{ Grade } \\
\hline $9^{\text {th }}$ & 50 & $25 \%$ & & \\
\hline $10^{\text {th }}$ & 50 & $25 \%$ & & \\
\hline $11^{\text {th }}$ & 50 & $25 \%$ & & \\
\hline $12^{\text {th }}$ & 50 & $25 \%$ & & \\
\hline Age & & & 15.930 & 1.391 \\
\hline 13 & 5 & $2.5 \%$ & & \\
\hline 14 & 26 & $13.0 \%$ & & \\
\hline 15 & 48 & $24.0 \%$ & & \\
\hline 16 & 51 & $25.5 \%$ & & \\
\hline 17 & 48 & $24.5 \%$ & & \\
\hline 18 & 16 & $8.0 \%$ & & \\
\hline 19 & 4 & $2.0 \%$ & & \\
\hline 20 & 1 & $.5 \%$ & & \\
\hline 21 & 1 & $.5 \%$ & & \\
\hline \multicolumn{5}{|l|}{ Father's Education } \\
\hline Uneducated/Below High School & 3 & $1.5 \%$ & & \\
\hline High School & 20 & $10.0 \%$ & & \\
\hline Graduate & 53 & $26.5 \%$ & & \\
\hline PG \& Non Professional & 76 & $38.0 \%$ & & \\
\hline PG \& Professional & 48 & $24.0 \%$ & & \\
\hline \multicolumn{5}{|l|}{ Mother's Education } \\
\hline Uneducated/Below High School & 72 & $36.0 \%$ & & \\
\hline High School & 37 & $18.5 \%$ & & \\
\hline Graduate & 30 & $15.0 \%$ & & \\
\hline PG \& Non Professional & 37 & $18.5 \%$ & & \\
\hline PG \& Professional & 24 & $12.0 \%$ & & \\
\hline
\end{tabular}

\section{Measures}

Student Stress Scale (SSS): For measuring stress typically experienced by the students, Student Stress Scale developed by Husain, Rashid, and Jahan (2006) was used. The scale consists of 57 items with the four point rating scale ranging from "no stress at all" (scored as 0) to "extreme stress" (scored as 3). This scale is unidimensional and aims to measure the level of stress experienced by students. The Cronbach Coefficient alpha of this scale is 0.96 . Content validity of the scale is satisfactory. The validity of the SSS against Dobson's Student Stress Inventory (Dobson \& Alban Metacalfe, 1983) was determined by the present researcher. For this purpose both the scales were administered on a sample of 100 students. The coefficient of correlation between the two scales was found to be .782 .

Life Orientation Test-Revised (LOT-R): Optimism was measured by the Life Orientation Test-Revised (Scheier, Carver, \& Bridges, 1994). It consists of 10 statements (3 positively worded, 3 negatively worded and 4 filler items). Only 6 of the 10 items on the revised LOT are used to derive an optimism score, and four filler items are not used for scoring purpose. Respondents are asked to indicate the extent of their agreement with each of the items using the following response format: $0=$ Strongly Disagree, $1=$ Disagree, $2=$ Neutral, $3=$ Agree and $4=$ Strongly Agree. Scoring of negatively worded items is done in reverse order. Scoring of these 6 items is then summed up to compute an overall optimism score with high score representing greater optimism 
and lower scores indicating lower optimism, often referred to as pessimism (Scheier et al., 1994). The inter-item correlations of the LOT-R ranged from .43 to .63 and the Chronbach's alpha is .78. The scale has been found to be fairly stable across time with sufficient convergent and discriminant validity. The LOT is valid and it has good temporal stability over 4 weeks $(\mathrm{r}=.79), 4$ month $(\mathrm{r}=.68)$, and 12 month $(\mathrm{r}=.60$; Scheier \& Carver, 1985, Scheier et al., 1994). Dispositional optimism has also adequate construct and predictive validity (Scheier \& Carver, 1987).

The Scale for Suicidal Ideation (SSI): Suicidal ideation among the students was assessed with the help of 19 item self-report Scale for Suicidal Ideation developed by Beck, Kovacs, and Weissman (1979). The SSI was designed to quantify the intensity of current conscious suicidal intent by scaling various dimensions of selfdestructive thoughts or wishes. The items assess the extent of suicidal thoughts and their characteristics as well as the respondent's attitude towards them; the extent of the wish to die, the desire to make an actual suicide attempt, and details of plans, if any; internal deterrents to an active attempt; and subjective feeling of control / or "courage" regarding a proposed attempt. Each item consists of three alternative statements graded in intensity from 0 to 2 . The instrument's total score is the sum of the individual item scores and may range from 0 (low ideation) to 38 (high ideation). In other words, a positive rating $(>1)$ on any of the ideation scale's 19 items is considered as a potential indicator of suicide ideation. Out of 19 items, 16 have positive and significant itemtotal correlations and a Cronbach alpha was .89 , which indicate high reliability of SSI and also support the validity of this scale (Beck et al., 1979). Validity of SSI was also indicated by the moderate correlations with clinical ratings of suicidal risk and self-harm (Beck et al., 1979).

Apart from the above, a Personal Data Sheet was used to get demographic information about adolescents.

\section{Procedure of Data Collection}

Prior to the data collection, the authorities of the educational institutes were approached for their permission and cooperation to collect data from their students. After obtaining permission with ensured cooperation the researcher visited the institutions and made all the necessary arrangements for the administration of the tests. The data were collected in class room situations. After getting the willingness of subjects, a congenial rapport was established to make them comfortable. The investigator visited the classrooms and took 2 to 3 minutes time to introduce herself and the purpose of her research to students. Then she distributed the copies of questionnaires (which contained Personal data sheet and 3 scales) to students. This was done with the help of the teacher concerned. Subjects were instructed to go through the instructions written in the questionnaires before answering each questionnaire. The instructions were also read to them loudly by the investigator, so that all students may follow them correctly. Examinees were asked not to leave any item unanswered. They were also asked to be free to ask if they had any queries. There was no time limit fixed for filling up the questionnaires. However, they were asked not to take unnecessarily long time. Most students completed /the questionnaires within approximately 35 to 40 minutes i.e. time allotted for one period. The general testing conditions were satisfactory and the procedure was uniform throughout the data collection. The same procedure was repeated in each class. After data collection, scoring of the responses was done according to the scoring procedure prescribed for each scale.

\section{Results of the Descriptive Statistics}

\section{Results}

SPSS 16.0 of Windows software was used for the statistical analyses. Means, Standard Deviations, Standard Error of Mean and obtained range of scores with possible score of the major variables are displayed in Table 2.

Table 2: Descriptive Statistics of Study Variables $(\mathrm{N}=200)$

\begin{tabular}{llll}
\hline Variables & Suicidal Ideation & Stress & Optimism \\
\hline Mean & 9.375 & 75.9400 & 15.290 \\
SD & 5.276 & 21.749 & 2.706 \\
SEM & .373 & 1.538 & .191 \\
Obtained Range & $0-28$ & $11-125$ & $8-21$ \\
Possible Score & $0-38$ & $0-171$ & $0-24$ \\
\hline
\end{tabular}

Correlation coefficients among the study variables are presented in Table 3. 
Table 3: Inter-correlations among Study Variables

\begin{tabular}{|c|c|c|c|c|c|c|c|c|}
\hline Variables & 1 & 2 & 3 & 4 & 5 & 6 & 7 & 8 \\
\hline 1.Suicidal Ideation & 1.00 & & & & & & & \\
\hline 2. Stress & $.556^{* *}$ & 1.00 & & & & & & \\
\hline 3 Optimism & $-.563^{* *}$ & $-.215^{* *}$ & 1.00 & & & & & \\
\hline 4. Age & .062 & -.053 & .083 & 1.00 & & & & \\
\hline 5. Gender ${ }^{\mathrm{a}}$ & $-.267^{* *}$ & .031 & $.163^{*}$ & -.123 & 1.00 & & & \\
\hline 6. PPGE & $-.322^{* *}$ & -.124 & $295^{* *}$ & $-.271^{* *}$ & .082 & 1.00 & & \\
\hline 7. Father's Education ${ }^{\text {b }}$ & $-.224^{* *}$ & -.097 & $.173^{*}$ & .004 & -.010 & $.162^{*}$ & 1.00 & \\
\hline 8.Mother'sEducation ${ }^{\mathrm{c}}$ & $-.186^{* *}$ & -.073 & $.148^{*}$ & .013 & $.139^{*}$ & $.145^{*}$ & $.479^{* *}$ & 1.00 \\
\hline
\end{tabular}

Note: $\mathrm{N}=200 .{ }^{*} \mathrm{p}<.05 .{ }^{*} \mathrm{p}<.01 ;{ }^{\mathrm{a}}$ Gender $(1=$ Male, $2=$ female $),{ }^{\mathrm{b}}$ Fathers' education $(1=$ Uneducated/Below High School, $2=\mathrm{High}$ School, 3 = Graduate, 4 = PG \& Non Professional, $5=$ PG \& Professional), ${ }^{\text {} M o t h e r ' s ~ E d u c a t i o n ~}(1=$ Uneducated/Below High School, $2=$ High School, 3 = Graduate, 4 = PG \& Non Professional, $5=$ PG \& Professional); PPGE= Percentage of marks in preceding Grade examination.

As expected, suicidal ideation was positively correlated with Stress $(r=.556, \mathrm{p}<.01)$ i.e., increased adolescents stress was associated with increased suicidal ideation. Whereas, it is observed from Table 3 that adolescent suicidal ideation bears significant negative relationship with optimism. These correlations are in the expected direction.

Table 3 also presents correlations between demographic variables and study variables/psychological variables. An inspection of this Table reveals that suicidal ideation was significantly, negatively related to gender, percentage of marks in preceding Grade examination (PPGE), father's education and mothers education- indicating high level of suicidal ideation among male adolescents, adolescents who had secured lower percentage of marks in earlier Grade, and whose father and mother were less educated. variables.

It is also observed from the Table 3 that stress was not significantly related to any of the demographic

Gender, percentage of marks in preceding Grade examination, father's education, and mother's education were significantly positively related to optimism.

Gender differences on the major study variables were explored through independent samples t-test.

Table 4: Gender Differences in the Study Variables

\begin{tabular}{|c|c|c|c|c|c|c|c|}
\hline & \multicolumn{3}{|c|}{ Gender } & & \multirow{3}{*}{$\begin{array}{c}\mathrm{t} \text {-value } \\
(\mathrm{df}=198)\end{array}$} & \multirow{3}{*}{\multicolumn{2}{|c|}{$\begin{array}{c}95 \% \text { CI } \\
\text { (Lower, Upper) }\end{array}$}} \\
\hline & \multicolumn{2}{|c|}{ Boys $(\mathrm{N}=100)$} & Girls $(N=100)$ & & & & \\
\hline & $\mathrm{M}$ & SD & $\begin{array}{ll}\mathrm{M} & \mathrm{SD} \\
\end{array}$ & & & & \\
\hline Suicidal Ideation & 10.780 & \begin{tabular}{l|l}
5.104 \\
\end{tabular} & 7.970 & 5.090 & $3.898 * * *$ & 1.388 & 4.232 \\
\hline Stress & 75.260 & 20.420 & 76.620 & 23.085 & .441 & -7.438 & 4.718 \\
\hline Optimism & 14.850 & 2.889 & 15.730 & 2.445 & $2.325 *$ & -1.626 & -.134 \\
\hline
\end{tabular}

Table 4 reflects the results of the t-test for examining the difference between male and female adolescents with regard to suicidal ideation, stress, and optimism. The results shown in Table 4 indicate that there were significant gender differences in suicidal ideation and optimism. Boys scored significantly higher on suicidal ideation, whereas girls scored significantly higher on optimism.

\section{Results of Hierarchical Regression Analyses}

Hierarchical regression analyses were performed to examine the utility of stress and optimism in predicting suicidal ideation. Consistent with Cohen and Cohen (1983), all variables within a given set were entered simultaneously. For the first step, demographic variables (viz., gender, percentage of marks in preceding grade examination, father's education, and mother's education) were entered into the regression equation. The inclusion of the main-effect of stress and optimism was involved in the second and third step respectively, and in the last and final step involved the interaction of Stress X Optimism. This procedure allowed the separate analyses of the independent contributions of demographic variables, stress, and optimism and the interaction between stress and the moderating variable. For reducing the problem of multicollinearity by reducing the size of any high correlation of the independent variable or the moderator variable with the new interaction variable, procedure outlined by Aiken and West (1991) was used that required all continuous variable should be converted into standard score and then standardized variables are multiplied together to create the interaction variable. Results of these analyses are presented in Tables 5 through 7.

The results of the hierarchical regression analysis for the total sample are set in Table 5. Noteworthy, gender $(\beta=-.242$, $\mathrm{t}$ - value $=-3.704, \mathrm{p}<.001)$, percentage in preceding grade examination $(\beta=-.270, \mathrm{t}-$ value $=$ $-4.128, \mathrm{p}<.001)$, and father's education $(\beta=-.167, \mathrm{t}-$ value $=-2.254, \mathrm{p}<.05)$ were found to be significant predictors of suicidal ideation, as demonstrated in step 1 . These variables accounted for a significant $19.5 \%\left(\mathrm{R}^{2}\right.$ $=.195, \mathrm{~F}=11.818, \mathrm{p}<.001)$ of the variance in suicidal ideation, gender and percentage of marks in preceding 
grade examination being the consistent predictor in all the four steps of analysis. The effect of these variables was, thus, controlled for further analysis.

Table 5: Hierarchical Multiple Regression analysis for Total sample $(\mathrm{N}=200)$.

\begin{tabular}{|c|c|c|c|c|}
\hline Variables & $\begin{array}{l}\text { Step1 } \\
\square\end{array}$ & $\begin{array}{l}\text { Step2 } \\
\square\end{array}$ & $\begin{array}{l}\text { Step3 } \\
\square\end{array}$ & $\begin{array}{l}\text { Step4 } \\
\square\end{array}$ \\
\hline Gender $^{\mathrm{a}}$ & $-.242 * * *$ & $-.265 * * *$ & $-.210 * * *$ & $-.198 * * *$ \\
\hline PPGE & $-.270 * * *$ & $-.211 * * *$ & $-.121 *$ & $-.121 *$ \\
\hline Mother's Education $^{c}$ & -.033 & -.016 & -.004 & -.030 \\
\hline Stress & & $.524 * * *$ & $.457 * * *$ & $.487 * * *$ \\
\hline Optimism & & & $-.378 * * *$ & $-.368 * * *$ \\
\hline $\mathbf{R}$ & .442 & .681 & .764 & .793 \\
\hline $\mathbf{R}^{2}$ & .195 & .463 & .584 & .628 \\
\hline$\square \mathbf{R}^{2}$ & .195 & .268 & .121 & .045 \\
\hline F change & $11.818 * * *$ & $96.840 * * *$ & $55.930 * * *$ & $23.062 * * *$ \\
\hline $\mathbf{F}$ & $11.818 * * *$ & $33.469 * * *$ & $45.110 * * *$ & $46.380 * * *$ \\
\hline
\end{tabular}

After controlling for demographic variables Stress was entered at step 2. The main effect of stress was found to be significant beyond $0.1 \%$ level $(\beta=.524$, t- value $=9.841, \mathrm{p}<.001)$. There was a substantial increase of .268 in $\mathrm{R}^{2}$ (F-change $=96.840, \mathrm{p}<.001$ ), indicating the unique contribution of stress (after controlling for demographic variables) in explaining variance in suicidal ideation to be as much as $26.8 \%$. Adding optimism at step 3 added significantly to the variance accounted for and explained an additional $12.1 \%$ of the variance (Fchange $=55.930, \mathrm{p}<.001$ ), significantly improving the prediction of suicide ideation above and beyond the contribution of the demographic variables and stress. Optimism was, however, a strong negative predictor of suicidal ideation $(\beta=-.378$, $\mathrm{t}$ - value $=-7.479, \mathrm{p}<.001)$.

The prediction of suicidal ideation was also significantly enhanced with addition of the interaction term of Stress X Optimism $\left(\Delta \mathrm{R}^{2}=.045, \mathrm{~F}\right.$-change $\left.=23.052, \mathrm{p}<.001\right)$, indicating that the nature of relationship between stress and suicidal ideation varied as a function of the optimism scores. As can be seen from $\beta$ values in Table 5, the Stress X Optimism interaction made a significant contribution to the prediction of suicidal ideation $(\beta=-.215, \mathrm{t}$ - value $=-4.802, \mathrm{p}=.000)$. The significant interactions support the moderating role of optimism in the relationship between stress and suicidal ideation.

Significant moderating effects were probed and plotted through simple slopes by using Aiken and West (1991) and Holmbeck's (2002) approach. These interactions were probed post-hoc using simple slope analysis to determine whether either slope significantly differed from zero. Significant interaction effects were probed by computing conditional moderator variables. Post hoc regressions were run with these conditional variables to compute simple slopes of the conditional effects of stress on suicidal ideation for each level of moderator variable i.e. at one standard deviation above the mean (+1SD) and one standard deviation below the mean (1SD; e.g., high optimism, low optimism). Because predictor and moderator variables are centered before computing regressions, the mean is always zero. In order to examine a significant interaction effect, the unstandardized regression coefficients were utilized to construct a prediction equation. Regression lines were calculated at plus-and-minus one standard deviation of the stress, and then plotted to examine the slope of the association between stress and suicidal ideation within each level of moderator variable i.e. high and low levels.

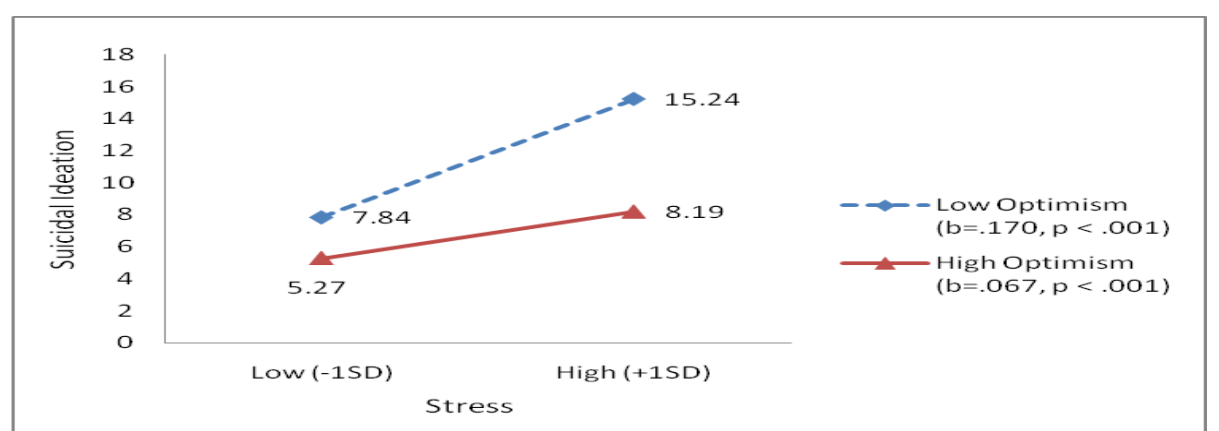

Figure 1. Plot of significant moderating effect in analysis of Stress X Optimism predicting suicidal ideation for total sample. 
The interaction between optimism and stress is displayed graphically in Figure 1. Post hoc probing of the simple slopes revealed significant relationships between stress and suicidal ideation in both high $(\mathrm{b}=.067, \mathrm{t}$ $=4.367, \mathrm{p}<.001)$ and low optimism $(\mathrm{b}=.170, \mathrm{t}=9.631, \mathrm{p}<.001)$ conditions. In other words, with respect to the regression of suicidal ideation on stress (Figure 1), results of post hoc probing revealed that the simple slopes for 1 SD below the mean and 1 SD above the mean of optimism were all significantly different from zero. The results of probing the interaction between stress and optimism to predict suicidal ideation, suggest a buffering effect. More specifically, students with high optimism were buffered against the effects of stress and reported the lowest level of suicidal ideation. In addition, using procedures outlined by Aiken and West (1991) for determining differences between simple slopes, the slope for low optimists (pessimists) was found to be significantly steeper than the slope for high optimists, $\mathrm{t}(196)=-4.507, \mathrm{p}<.001$. In other words, Low optimists (pessimists) as compared to high optimists had higher increase in suicidal ideation under high stress condition. The results of the analysis for boys sample are set in Table 6. Noteworthy, percentage of marks in preceding Grade examination and father's education $(\beta=-.213$, $\mathrm{t}$ - value $=-2.210, \mathrm{p}<.05$ and $\beta=-.257$, $\mathrm{t}$ - value $=-2.453, \mathrm{p}$ $<.05$, respectively) were found to be significant predictors of suicidal ideation, as demonstrated in step 1 . Demographic variables accounted for a significant $18.3 \%\left(\mathrm{R}^{2}=.183, \mathrm{~F}=7.176, \mathrm{p}<.001\right)$ of the variance in suicidal ideation.

Table 6 : Hierarchical Multiple Regression analysis for Boys $(\mathrm{N}=100)$

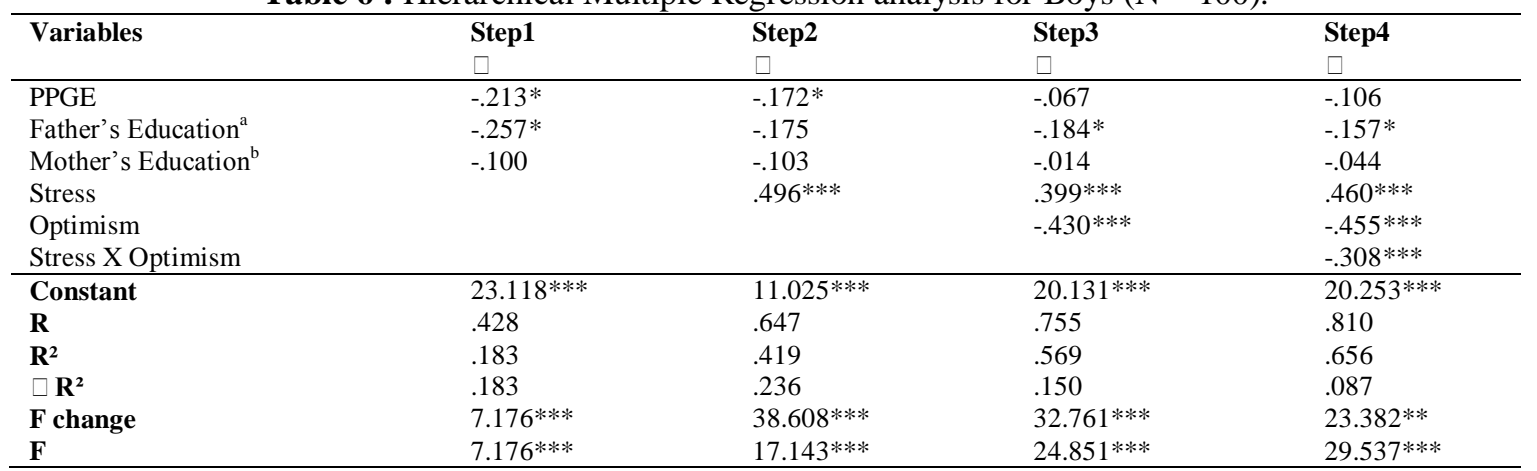

Note. $\beta=$ Standardized regression coefficient. $* * * p<.001,{ }^{*} * \mathrm{p}<.01,{ }^{*} \mathrm{p}<.05$; ${ }^{\mathrm{a}}$ Father's education $(1=$ Uneducated/Below High School, 2 = High School, 3 = Graduate, $4=$ PG \& Non Professional, $5=$ PG \& Professional); 'Mother's Education (1 = Uneducated/Below High School, 2 = High School, 3 = Graduate, 4 = PG \& Non Professional, 5 = PG \& Professional); PPGE = Percentage of marks in preceding Grade examination.

After controlling for demographic variables, the main effect of stress was found to be significant beyond $0.1 \%$ level $(\beta=.496, \mathrm{t}-$ value $=6.214, \mathrm{p}<.001)$. There was a substantial increase of .236 in $\mathrm{R}^{2}(\mathrm{~F}-$ change $=38.608, \mathrm{p}<.001)$, indicating the unique contribution of stress in explaining variance in suicidal ideation to be as much as $23.6 \%$. Entering optimism at step 3 added significantly to the variance accounted for and explained an additional $15 \%$ of the variance $\left(\Delta \mathrm{R}^{2}=.150\right.$, F-change $\left.=32.761, \mathrm{p}<.001\right)$, significantly improving the prediction of suicide ideation above and beyond the contribution of the demographic variables and stress. Optimism was, however, a strong negative predictor of boys' suicidal ideation $(\beta=-.430$, t- value $=$ 5.724, $\mathrm{p}<.001)$.

Lastly, at step 4, the prediction of suicidal ideation was also enhanced with addition of the interaction term of Stress X Optimism $\left(\Delta \mathrm{R}^{2}=.087, \mathrm{~F}\right.$-change $\left.=23.382, \mathrm{p}<.001\right)$, indicating that the nature of relationship between stress and suicidal ideation varied as a function of the optimism. As can be seen from $\beta$ values in Table 6 , the Stress X Optimism interaction made a significant contribution to the prediction of suicidal ideation $(\beta=$ $.308, \mathrm{t}-$ value $=-4.836, \mathrm{p}=.000$ ). The significant interaction supports the moderating role of optimism in the relationship between stress and suicidal ideation in boys. The results of the post hoc analyses are depicted in Figure 2. 


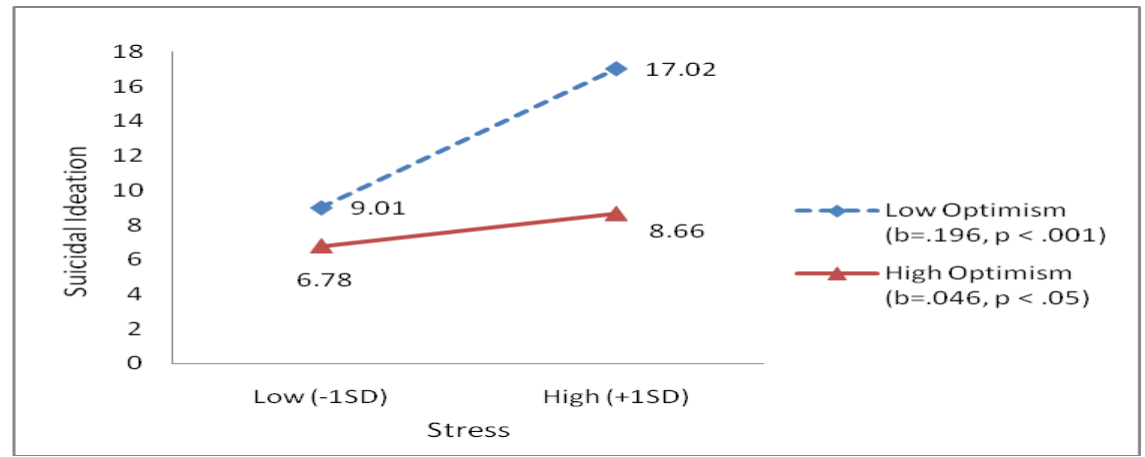

Figure 2. Plot of significant moderating effect in analysis of Stress X Optimism predicting suicidal ideation for boys.

To examine the nature of above significant interactions, post hoc statistical testing was conducted and simple slopes were plotted using the same procedures as used for total sample. Figure 2 reveals that the slope for boys with lower optimism $(b=.196, t=7.548, \mathrm{p}<.001)$ and higher optimism $(b=.046, t=2.150, p<.05)$ significantly differed from zero. Overall, the significant interaction terms signify that the regression of suicidal ideation on stress vary across the range of optimism $(\mathrm{t}=-4.455, \mathrm{p}<.001)$. More specifically, the predicted values of suicidal ideation in the graph show that at low level of stress, boys with low optimism have an increased likelihood of suicidal ideation as compared to boys with high optimism. As stress increases risk for suicidal thoughts also increases for individuals at both levels of optimism, although the low optimist group is at the greatest risk.

Table 7: Hierarchical Multiple Regression analysis for Girls $(\mathrm{N}=100)$.

\begin{tabular}{lllll}
\hline Variables & Step1 & Step2 & Step3 & Step4 \\
& $\square$ & $\square$ & $\square$ & $\square$ \\
\hline PPGE & $-.320 * * *$ & $-.245^{* *}$ & $-.163^{*}$ & $-.147^{*}$ \\
Father's Education $^{\mathrm{a}}$ & -.077 & -.107 & -.007 & -.021 \\
Mother's Education $^{\mathrm{b}}$ & .006 & .061 & -015 & -.019 \\
Stress & & $.584 * * *$ & $.527 * * *$ & $.538^{* * *}$ \\
Optimism & & & $-.356 * * *$ & $-.324 * * *$ \\
Stress X Optimism & & & & $-.151^{*}$ \\
\hline Constant & $21.097 * * *$ & $8.622^{*}$ & $16.883^{* * *}$ & $15.312^{* * *}$ \\
$\mathbf{R}$ & .331 & .666 & .742 & .757 \\
$\mathbf{R}^{2}$ & .110 & .443 & .551 & .572 \\
$\square \mathbf{R}^{\mathbf{2}}$ & .110 & .333 & .108 & .021 \\
$\mathbf{F}$ change & $3.943^{*}$ & $56.847 * * *$ & $22.635^{* * *}$ & $4.636^{*}$ \\
$\mathbf{F}$ & $3.943^{*}$ & $18.889 * * *$ & $23.080^{* * *}$ & $20.750^{* * *}$ \\
\hline
\end{tabular}

Note. $\beta=$ Standardized regression coefficient. $* * * p<.001, * * p<.01,{ }^{*} \mathrm{p}<.05 ;{ }^{\mathrm{a}}$ Father's education $(1=$ Uneducated/Below High School, 2

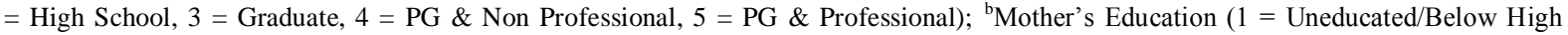
School, 2 = High School, 3 = Graduate, 4 = PG \& Non Professional, 5 = PG \& Professional); PPGE = Percentage of marks in preceding Grade examination.

The results of the hierarchical regression analysis for girls sample are set in Table 7. Again, it was noteworthy that percentage of marks in preceding grade examination $(\beta=-.320$, $\mathrm{t}$ - value $=-3.322$, $\mathrm{p}<.001)$ was found to be significant predictor of suicidal ideation, as demonstrated in step 1. Demographic variables accounted for an $11 \%\left(\mathrm{R}^{2}=.110, \mathrm{~F}=3.943, \mathrm{p}=0.011\right)$ of the variance in suicidal ideation.

After controlling for demographic variables, the main effect of stress was found to be significant beyond $0.1 \%$ level $(\beta=.584, \mathrm{t}-$ value $=7.540, \mathrm{p}<.001)$. There was a substantial increase of .333 in $\mathrm{R}^{2}(\mathrm{~F}-$ change $=56.847, \mathrm{p}<.001)$, indicating the unique contribution of stress in explaining variance in suicidal ideation to be as much as $33.3 \%$. Entering optimism at step 3 added significantly to the variance accounted for and explained an additional $10.8 \%$ of the variance $\left(\Delta \mathrm{R}^{2}=.108\right.$, F-change $\left.=22.635, \mathrm{p}<.001\right)$, significantly improving the prediction of suicide ideation above and beyond the contribution of the demographic variables and stress. Optimism was a significant negative predictor of girls' suicidal ideation $(\beta=-.356, \mathrm{t}-\mathrm{value}=-4.758$, $\mathrm{p}<.001)$.

In fourth and final block, the prediction of suicidal ideation was marginally enhanced with addition of the interaction term of Stress X Optimism and add significantly to the amount of variance accounted for in suicidal ideation $\left(\Delta \mathrm{R}^{2}=.021, \mathrm{~F}\right.$-change $\left.=4.636, \mathrm{p}=.034\right)$. As can be seen from $\beta$ value in Table 7 , Stress $\mathrm{X}$ Optimism made a significant contribution to the prediction of suicidal ideation in girls. The significant interaction supports the moderating role of optimism in the relationship between stress and suicidal ideation in girls. The results of the post hoc analyses are depicted in Figure 3. 


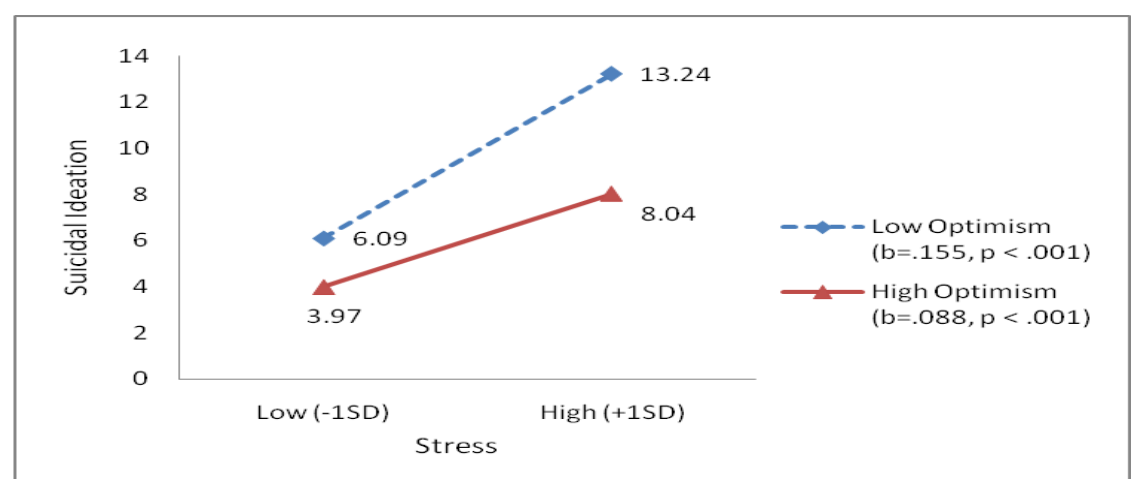

Figure 3. Plot of significant moderating effect in analysis of Stress X Optimism predicting suicidal ideation for Girls.

Figure 3 reveals that the slope for girls with lower optimism $(b=.155, t=7.173, p<.001)$ and higher optimism $(\mathrm{b}=.088, \mathrm{t}=4.345, \mathrm{p}<.001)$ significantly differed from zero. The figure shows, there was a significant positive relation between stress and suicidal ideation at both high and low levels of optimism. However, the beta value (showing the regression of suicidal ideation on stress) for high optimism group is lesser than that for the low optimism group. In other words, the slope for low optimism was found to be significantly sharper than the slope for high optimism, $\mathrm{t}(96)=-2.328, \mathrm{p}<.05$.

\section{Discussion}

As prevention of suicidal incidents is a challenging task ahead of health practitioners, psychiatrists, and psychologists, the present study was undertaken to investigate the role of stress and optimism in suicidal ideation. The results of this study find support from the study conducted by Mackenzie et al. (2011) who, among college students, found that the frequency of depression was similar for men and women but thought of suicide was higher for men than women. Stewart, Donaghey, Deary, and Ebmeier (2008) also found that men scored slightly higher than women on suicidal thoughts.

Though our findings are supported by the above studies, the review of earlier research conducted in India and abroad suggest contradictory results indicating higher level and prevalence of suicidal ideation among girls (Allison, Roeger, Martin, \& Keeves, 2001; De Man, Leduc, \& Labréche-Gauthier, 1993; Laghi, Baiocco, D'Alessio, \& Gurrieri, 2009; Pronovost, Côté, \& Ross, 1990; Sharma, Grover, \& Chaturvedi, 2008; Sidhartha \& Jena, 2006; Ulusoy \& Demir, 2005; Waldrop et al., 2007; Yoder, Whitbeck, Hoyt, \& LaFromboise, 2006) while completed suicides to be high among boys. One explanation that seem to be appropriate for our findings may be comparatively higher level of anxiety experienced by Indian boys (Deb, Chatterjee, \& Walsh, 2010). According to these researchers, the difference may be attributed to cultural practices in Indian society. Despite the social changes brought about by globalization, underlying patriarchal structure persists (Da Costa, 2008, as cited in Deb et al., 2010) wherein boys continue to face more pressure regarding their choice of vocation and future career (Deb, 2001). These adolescents also perceive comparatively higher expectations from their parents which put them at risk for psychological distress (Shaheen, 2009).

One of the psychosocial predictors explored in the present paper was stress. Stress has emerged as potentially significant predictor of suicidal ideation among adolescents even after controlling for the effect of demographic variables such as gender, PPGE, father's education, and mother's education and has accounted for as large as $26.8 \%$ of the variance. The present finding supported the hypothesis 1 and is consistent with earlier researches. Bonner and Rich (1987) found that suicidal students had experienced more recent stress than nonsuicidal students including stress over exams. Studies conducted on suicidal ideation have indicated that recent stressful life events are related to low mental health including suicidal ideation (Flannery, Singer, \& Wester, 2001; Yang \& Clum, 1996) and that recency and degree of stress are significant in the prediction of degree and recency of suicidal ideation in students (Huff, 1999). Cluster of life events and life styles (Hintikka et al., 2009) and daily stresses (Izadinia, Amiri, Jahromi, \& Hamidi, 2010) also have a positive relationship with suicidal ideation.

Another factor that was investigated in relation to suicidal ideation, was dispositional optimism. Consistent with our second hypothesis and with previous research (Cato, 2012; Hirsch, Conner, et al., 2007; Sánchez-Teruel et al., 2013), the findings of both correlation and regression analyses of this study demonstrate that adolescents with low optimism (pessimists) are more likely to experience higher level of suicidal ideation. Roberts et al. (1998) also found a positive relationship between suicidal thinking and dispositional pessimism. Additionally, Lynch et al. (1999) reported that greater pessimistic thinking at baseline predicted the development of suicidal ideation one year later. The beneficial effect of optimism may be seen across all cultures. In a cross cultural study on suicidal ideation, Abdel-Khalek and Lester (2002) concluded that pessimism was one of the several predictors of suicidal ideation for both Kuwaiti and American students. 
Moreover, Priester and Clum (1992) in college students found that explanatory style was predictive of hopelessness, depression and suicidal ideation with optimistic explanatory style resulting in lower levels of depression, hopelessness and suicidal ideation and pessimistic explanatory style resulting in higher levels.

Consistent with our third hypothesis, the findings of the present study add support for the role of dispositional optimism as a stress buffering factor in suicidal ideation. The positive association between stress and suicidal ideation is found to be significantly exacerbated for low optimists (pessimists), than for high optimists (Figure 1). High optimists are at lower risk of suicidal ideation at both low and high levels of stress as compared to low optimists who experience higher level of suicidal ideation and whose risk for suicidal ideation is increased in high magnitude under high stress condition.

This result is consistent with findings by Hirsch, Wolford, et al., (2007), in which dispositional optimism moderated the relationships between negative life events and current suicide ideation and previous suicide attempts, after controlling for hopelessness and severity of depression among college students. Hirsch, Wolford, LaLonde, Brunk, and Parker-Morris (2009) also suggested that optimistic explanatory style mitigates the influence of negative and potentially traumatic life events on thoughts of suicide, above and beyond the effects of hopelessness and depression. Optimism has a buffering effect for both boys and girls students (Figure $2 \& 3$, respectively). Scheier and Carver (1993) and Puskar, Sereika, Lamb, Tusaie-Mumford, and McGuiness (1999) found that dispositional optimists cope more adaptively than dispositional pessimists and are more likely to tackle problems directly rather than avoiding them. Dispositional optimists are more likely than dispositional pessimist to accept and attempt to change uncontrollable situations, strive to overcome adversity, and persevere toward the accomplishment of goals (Scheier, Carver, \& Bridges, 2001). However, Khosla and Hanghal (2004), among undergraduate students found that optimists as compared to pessimists displayed higher cognitive and physical resources rather than in different coping strategies.

Dispositional optimism may also be a malleable and trainable attribute which is assumed to be stable and trait like (Schwarzer, 1999; Wrosch, Scheier, Miller, Schulz, \& Carver, 2003). There is ample evidence suggesting that depression can be reduced by training the individuals to think optimistically (Hawkins \& Miller, 2003; Vaillant, 2003) and "perhaps similar techniques could be used to decrease suicide ideation and behaviors in these at-risk populations" (Hirsch, Conner, et al., 2007, p. 182).

Though, in the present research, the effect of the demographic variables was controlled through the hierarchical regression analyses, their contribution in the prediction of suicidal ideation cannot be ignored. These variables accounted for $19.5 \%$ of the total variance in suicidal ideation in the total sample. Boys are at higher risk to have suicidal thoughts. Percentage of marks in previous Grade examination was significantly negatively related to suicidal ideation. Lower percentage of marks significantly predicted suicidal ideation among adolescents. This finding is consistent with some previous studies (Dubow, Kausch, Blum, Reed, \& Bush, 1989; Hesketh, Ding, \& Jenkins, 2002; Martin, Richardson, Bergen, Roeger, \& Allison, 2005). Additionally, a study performed on adolescents found that failing academic performance (compared to above average) was associated with a fivefold increased likelihood of a suicide attempt, controlling for self-esteem, locus of control and depressive symptoms (Richardson, Bergen, Martin, Roeger, \& Allison, 2005). Recently, Taliaferro and Muehlenkamp (2014) found in their study that apart from other factor academic achievement emerged as important protective factors to differentiate adolescents groups of no suicidality, suicidal ideation only, and suicide attempt. The present study also found that father's education was significantly negatively related to suicidal ideation suggesting high suicidal ideation among those whose father's education was low.

Our fourth hypothesis stated that predictors of suicidal ideation for boys and girls will be different. A careful analysis of the results reveals that our fourth hypothesis is partially confirmed. Demographic variables were found to account for a significant $18.3 \%$ of the variance in suicidal ideation in boys and only $11 \%$ of the variance in girls. Boys with lower levels of father's education showed more suicidal ideation whereas, for girls father's education did not significantly contribute to suicidal ideation. However, boys and girls with lower percentage of marks in preceding grade examination were equally likely to show higher suicidal ideation. Stress had significant positive predictive relationship whereas optimism had negative predictive relationship with suicidal ideation for both boys and girls. Similarly for boys, interaction between stress and optimism added significantly to the prediction of suicidal ideation, suggesting that optimism did moderate the relation between stress and suicidal ideation for both boys and girls.

\section{Conclusion}

This study examined the relationship between stress, optimism and suicide ideation in samples of adolescent students. The conclusion is, therefore, offered that the constructs of stress, optimism, and suicidal ideation can provide a meaningful basis for understanding risk and protective factors of students' suicidal thinking and would help the health- care professionals, counsellors, teachers, and parents in understanding the dynamics of suicidal ideation among adolescents, i.e. how high stress which is peculiar to the stage of 
adolescence particularly students may have serious consequences in the form of suicidal ideas and that optimistic thinking would be helpful in coping with the stresses of this stage so as to avoid its harmful effects.

\section{References}

[1]. Abdel-Khalek, A., \& Lester, D. (2002). Can personality predict suicidality? A study in two cultures. International Journal of Social Psychiatry, 48(3), 231-239. doi:10.1177/002076402128783271

[2]. Aiken, L. S., \& West, S. G. (1991). Multiple Regression: Testing and interpreting interactions. Newbury Park, London: Sage Publication, Inc.

[3]. Allison, S., Roeger, L., Martin, G., \& Keeves, J. (2001). Gender differences in the relationship between depression and suicidal ideation in young adolescents. Australian and New Zealand Journal of Psychiatry, 35(4), 498-503. doi:10.1046/j.14401614.2001.00927.x

[4]. Baum, A. (1990). Stress, intrusive imagery, and chronic distress. Health Psychology, 9(6), 653-675.

[5]. Beck, A. T., Kovacs, M., \& Weissman, A. (1979). Assessment of suicide intention: The Scale for Suicide Ideation. Journal of Consulting and Clinical Psychology, 47, 343-352.

[6]. Blankstein, K. R., Lumley, C. H., \& Crawford, A. (2007). Perfectionism, hopelessness, and suicide ideation: Revisions to diathesisstress and specific vulnerability models. Journal of Rational-Emotive \& Cognitive-Behavior Therapy, 25(4), 279-319. doi:10.1007/s10942-007-0053-6

[7]. Bonner, R. L., \& Rich, A. R. (1987). Toward a predictive model of suicidal ideation and behaviour: Some preliminary data in college students. Suicide and Life-Threatening Behavior, 17, 50-63.

[8]. Cato, T. A. (2012). The relationship among suicide ideation, depression, and optimism. XULAneXUS: Xavier University of Louisiana's Undergraduate Research Journal, 10 (1), 21-26.

[9]. Chia, B. H. (1999). Too young to die: an Asian perspective on youth suicide. Times Books International, Singapore.

[10]. Cohen, J., \& Cohen, P. (1983). Applied multiple regression/correlation analysis for the behavioral sciences (2nd ed.). Hillsdale, NJ: Erlbaum.

[11]. Cole, D. E., Protinsky, H. O., \& Cross, L. H. (1992). An empirical investigation of adolescent suicidal ideation. Adolescence, 27(108), 813-818.

[12]. De Man, A. F., Leduc, C. P., \& Labréche-Gauthier, L. (1993). Correlates of suicidal ideation in French-Canadian adolescents: Personal variables, stress, and social support. Adolescence, 28, 819-830.

[13]. Deb, S. (2001, October). A study on the negative effects of academic stress. Paper presented at the International Seminar on Learning and Motivation, Kedah Darul Aman, Malaysia.

[14]. Deb, S., Chatterjee, P., \& Walsh, K. (2010). Anxiety among high school students in India: Comparisons across gender, school type, social strata and perceptions of quality time with parents. Australian Journal of Educational \& Developmental Psychology, 10, 1831.

[15]. Dobson, C. B., \& Alban Metacalfe, R. J. (1983). Reliability and validity of the student stress inventory. British Journal of Educational Psychology, 53(1), 121-125.

[16]. Dubow, E. F., Kausch, D. F., Blum, M. C., Reed, J., \& Bush, E. (1989). Correlates of suicidal ideation and attempts in a community sample of junior high and high school students. Journal of Clinical Child Psychology, 18(2), 158-166.

[17]. Flannery, D. J., Singer, M. I., \& Wester, K. (2001). Violence exposure, psychological trauma, and suicide risk in a community sample of dangerously violent adolescents. Journal of the American Academy of Child and Adolescent Psychiatry, 40, 435-442.

[18]. Harter, S., Marold, D. B., \& Whitesell, N. R. (1992). Model of psychological risk factors leading to suicidal ideation in you ng adolescents. Developmental Psychopathology, 4, 167-188.

[19]. Hawkins, M. T., \& Miller, R. J. (2003). Cognitive vulnerability and resilience to depressed mood. Australian Journal of Psychology, $55,176-183$.

[20]. Hesketh, T., Ding, Q. J., \& Jenkins, R. (2002). Suicide ideation in Chinese adolescents. Social Psychiatry and Psychiatric Epidemiology, 37(5), 230-235.

[21]. Hintikka, J., Koivumaa-Honkanen, H., Lehto, S. M., Honkalampi, T. T. K., Haatainen, K., \& Viinamäki, H. (2009). Are factors associated with suicidal ideation true risk factors? A 3 -year prospective follow-up study in a general population. Social Psychiatry and Psychiatric Epidemiology, 44, 29-33. doi:10.1007/s00127-008-0401-6

[22]. Hirsch, J. K., \& Conner, K. R. (2006). Dispositional and explanatory style optimism as potential moderators of the relationship between hopelessness and suicidal ideation. Suicide and Life-Threatening Behavior, 36(6), 661-669.

[23]. Hirsch, J. K., Conner, K. R., \& Duberstein, P. R. (2007). Optimism and suicide ideation among young adult college students. Archives of Suicide Research, 11, 177-185.

[24]. Hirsch, J. K., Duberstein, P., Conner, K. R., Heisel, M. J., Beckman, A., \& Conwell, Y. (2007a). Future orientation and suicide ideation and attempts in depressed adults ages 50 and over. American Journal of Geriatric Psychiatry, 14, $752-757$.

[25]. Hirsch, J. K., Duberstein, P., Conner, K. R., Heisel, M. J., Beckman, A., \& Conwell, Y. (2007b). Future orientation moderates the relationship between functional status and suicide ideation in depressed adults. Depression and Anxiety, 24(3), 196-201.

[26]. Hirsch, J. K., Wolford, K., LaLonde, S. M., Brunk, L., \& Morris, A. P. (2007). Dispositional optimism as a moderator of the relationship between negative life events and suicide ideation and attempts. Cognitive Therapy and Research, 31, 533-546. doi:10.1007/s10608-007-9151-0

[27]. Hirsch, J. K., Wolford, K., LaLonde, S. M., Brunk, L., \& Parker-Morris, A. (2009). Optimistic explanatory style as a moderator of the association between negative life events and suicide ideation. Crisis, 30(1), 48-53.

[28]. Holmbeck, G. N. (2002). Post-hoc probing of significant moderational and mediational effects in studies of pediatric populations. Journal of Pediatric Psychology, 27, 87-96.

[29]. Holmes, T., \& Rahe, R. (1967). The social readjustment rating scale. Journal of Psychosomatic Research, 12, $213-233$.

[30]. Huff, C. O. (1999). Source, recency and degree of stress in adolescence and suicide ideation. Adolescence, 34(133), 81-89.

[31]. Husain, A., Rashid, T., \& Jahan, M. (2006). Student Stress Scale. In A. Hussain \& M. I. Khan (Eds.), Recent Trends in Human Stress Management (pp. 254-257). New Delhi: Global Vision Publishing House.

[32]. Izadinia, N., Amiri, M., Jahromi, R. G., \& Hamidi, S. (2010). A study of relationship between suicidal ideas, depression, anxiety, resiliency, daily stresses and mental health among Tehran university students. Procedia-Social and Behavioral Sciences, 5, 15151519. doi:10.1016/j.sbspro.2010.07.335

[33]. Khosla, M., \& Hanghal, E. N. (2004). The role of optimism and pessimism in coping with stress. Journal of Personality and Clinical Studies, 20, 71-78. 
[34]. Kumar, S., \& Singh, A. P. (2006). Stress state and its relationship with academic performance among students. In A. Husain \& M. I. Khan (Eds.), Recent trends in human stress management (pp. 55-66). New Delhi: Global Vision Publishing House.

[35]. Laghi, F., Baiocco, R., D'Alessio, M., \& Gurrieri, G. (2009). Suicidal ideation and time perspective in high school students. European Psychiatry, 24, 41-46. doi:10.1016/j.eurpsy.2008.08.006

[36]. Lazarus, R. S., \& Folkman, S. (1984). Stress, Appraisal, and Coping. New York: Springer.

[37]. Lynch, T. R., Johnson, C. S., Mendelson, T., Robins, C. J., Krishnan, K. R. K., \& Blazer, D. G. (1999). New onset and remission of suicidal ideation among a depressed adult sample. Journal of Affective Disorders, 56(1), 49-54.

[38]. Mackenzie, S., Wiegel, J. R., Mundt, M., Brown, D., Saewyc E., Heiligenstein, E., ...Fleming, M. (2011). Depression and suicide ideation among students accessing campus health care. American Journal of Orthopsychiatry, 81(1), 101-107. doi:10.1111/j.19390025.2010.01077.x

[39]. Martin, G., Richardson, A. S., Bergen, H. A., Roeger, L., \& Allison, S. (2005). Perceived academic performance, self-esteem and locus of control as indicators of need for assessment of adolescent suicide risk: implications for teachers. Journal of Adolescence, 28, 75-87. doi:10.1016/j.adolescence.2004.04.005

[40]. Masuda, M., \& Holmes, T. H. (1967). Magnitude estimations of social readjustments. Journal of Psychosomatic Research, 11, 219225 .

[41]. National Crime Record Bureau (2013). Accidental Deaths and Suicides in India. New Delhi: Ministry of Home Affairs, Government of India.

[42]. O’Carroll, P. W., Berman, A. L., Maris, R. W., Moscicki, E. K., Tanney, B. L., \& Silverman, M. M. (1996). Beyond the Tower of Babel: A nomenclature for suicidology. Suicide and Life-Threatening Behavior, 26, 237-252.

[43]. Priester, M. J., \& Clum, G. A. (1992). Attributional style as a diathesis in predicting depression, hopelessness, and suicide ideation in college students. Journal of Psychopathology and Behavioral Assessment, 14, 111-122.

[44]. Pronovost, J., Côté, L., \& Ross, C. (1990). Epidemiological study of suicidal behavior among secondary school students. Canada's Mental Health, 38, 9-14.

[45]. Puskar, K., Sereika, S., Lamb, J., Tusaie-Mumford, K., \& McGuiness, T. (1999). Optimism and its relationship to depression, coping anger, and life events in rural adolescents. Issues in Mental Health Nursing, 20, 115-130.

[46]. Reynolds, W. M. (1988). Suicidal Ideation Questionnaire: Professional manual. Odessa, FL: Psychological Assessment Resources.

[47]. Richardson, A. S., Bergen, H. A., Martin, G., Roeger, L., \& Allison, S. (2005). Perceived academic performance as an indicator of risk of attempted suicide in young adolescents. Archives of Suicide Research, 9, 163-176.

[48]. Roberts, R. E., Roberts, C. R., \& Chen, Y. R. (1998). Suicidal thinking among adolescents with a history of attempted suicide. Journal of the American Academy of Child and Adolescent Psychiatry, 37, 1294-1300.

[49]. Sánchez-Teruel, D., García-León, A., \& Muela-Martínez, J. A. (2013). High suicidal ideation and psychosocial variables in university students. Electronic Journal of Research in Educational Psychology, 11(2), 429-450.

[50]. Sarafino, E. P. (1994). Health Psychology-Biopsycho-social Interactions. New York: John Wiley \& Sons, Inc.

[51]. Scheier, M. F., \& Carver, C. S. (1985). Optimism, coping, and health: Assessment and implications of generalized outcome expectancies. Health Psychology, 4, 219-247.

[52]. Scheier, M. F., \& Carver, C. S. (1987). Dispositional optimism and physical well-being: The influence of generalized outcome expectancies on health. Journal of Personality, 55, 169-210.

[53]. Scheier, M. F., \& Carver, C. S. (1992). Effects of optimism on psychological and physical well-being: Theoretical overview and empirical update. Cognitive Therapy and Research, 16, 201-228.

[54]. Scheier, M. F., \& Carver, C. S. (1993). On the power of positive thinking: The benefits of being optimistic. Current Directions in Psychological Science, 2, 26-30.

[55]. Scheier, M. F., Carver, C. S., \& Bridges, M. W. (1994). Distinguishing optimism from neuroticism (and trait anxiety, self-mastery, and self-esteem): A reevaluation of the Life Orientation Test. Journal of Personality and Social Psychology, 67, 1063-1078.

[56]. Scheier, M. F., Carver, C. S., \& Bridges, M. W. (2001). Optimism, pessimism, and psychological well-being. In E. C. Chang (Ed.), Optimism and pessimism: Implications for theory, research, and practice (pp. 189-216). Washington, DC: American Psychological Association.

[57]. Scheier, M. F., Weintraub, J. K., \& Carver, C. S. (1986). Coping with stress: Divergent strategies of optimists and pessimists. Journal of Personality and Social Psychology, 51, 1257-1264.

[58]. Schwarzer, R. (1999). Self-regulatory processes in the adoption and maintenance of health behaviors: The role of optimism, goals, and ghreats. Journal of Health Psychology, 4, 115-127.

[59]. Seligman, M. E. P., \& Csikszentmihalyi, M. (2000). Positive psychology: An introduction. American Psychologist, 55(1), 5-14.

[60]. Selye, H. (1956). The stress of life. New York: McGraw-Hill.

[61]. Shaheen, F. (2009). A study of parental expectations, attributional styles and coping strategies of students experiencing psychological distress. (Unpublished doctoral dissertation). Aligarh Muslim University, India

[62]. Sharma, R., Grover, V. L., \& Chaturvedi, S. (2008). Suicidal behavior amongst adolescent students in south Delhi. Indian Journal of Psychiatry, 50(1), 30-33.

[63]. Sidhartha, T., \& Jena, S. (2006). Suicidal behaviors in adolescents. Indian Journal of Paediatrics, 73(9), 783-788.

[64]. Stewart, M. E., Donaghey, C., Deary, I. J., \& Ebmeier, K. P. (2008). Suicidal thoughts in young people: Their frequency and relationships with personality factors. Personality and Individual Differences, 44, 809-820.

[65]. Taliaferro, L. A., \& Muehlenkamp, J. J. (2014). Risk and protective factors that distinguish adolescents who attempt suicide from those who only consider suicide in the past year. Suicide and Life- Threatening Behavior, 44(1), 6-22. doi: 10.1111/sltb.12046

[66]. Ulusoy, M. D., \& Demir, N. O. (2005). Suicidal ideation in Turkish adolescents. Social Behavior and Personality, 33(6), 541-552.

[67]. Ung, E. K. (2003). Youth suicide and parasuicide in Singapore. Annals Academy of Medicine Singapore, $32,1-7$.

[68]. Vaillant, G. E. (2003). Mental health. American Journal of Psychiatry, 160, 1373-1384.

[69]. Waldrop, A. E., Hanson, R. F., Resnick, H. S., Kilpatrick, D. G., Naugle, A. E., \& Saunders, B. E. (2007). Risk factors for suicidal behavior among a national sample of adolescents: Implications for prevention. Journal of Traumatic Stress, 20(5), 869-879.

[70]. Wrosch, C., Scheier, M. F., Miller, G. E., Schulz, R., \& Carver, C. S. (2003). Adaptive self-regulation of unattainable goals: Goal disengagement, goal reengagement, and subjective well-being. Personality and Social Psychology Bulletin, 29, 1494-1508.

[71]. Yang, B., \& Clum, G. A. (1996). Effects of early negative life experiences on cognitive functioning and risk for suicide: A review. Clinical Psychology Review, 16, 177-95.

[72]. Yoder, K. A., Whitbeck, L. B., Hoyt, D. R., \& LaFromboise, T. (2006). Suicidal ideation among American Indian youths. Archives of Suicide Research, 10, 177-190. doi:10.1080/13811110600558240 